\title{
CONSTITUCIONALISMO DEMOCRÁTICO: ENTRE AS TEORIAS POPULARES DO CONSTITUCIONALISMO E UM NOVO APORTE DO PAPEL DAS CORTES NA DEMOCRACIA
}

\author{
DEMOCRATIC CONSTITUTIONALISM: BETWEEN THE POPULAR \\ THEORIES OF THE CONSTITUTIONALISM AND A NEW PERSPECTIVE \\ OF THE ROLE PLAYED BY COURTS IN DEMOCRACY
}

\author{
Ingrid Cunha Dantas \\ Universidade Federal de Minas Gerais - UFMG - (Belo Horizonte, Minas Gerais, Brasil) \\ Bernardo Gonçalves Fernandes \\ Universidade Federal de Minas Gerais - UFMG - (Belo Horizonte, Minas Gerais, Brasil)
}

Recebimento: 22 nov. 2018

Aceitação: 13 maio 2019

\begin{abstract}
Como citar este artigo / How to cite this article (informe a data atual de acesso / inform the current date of access):
DANTAS, Ingrid Cunha; FERNANDES, Bernardo Gonçalves. Constitucionalismo democrático: entre as teorias populares do constitucionalismo e um novo aporte do papel das cortes na democracia. Revista da Faculdade de Direito UFPR, Curitiba, PR, Brasil, v. 64, n. 2, p. 61-88, maio/ago. 2019. ISSN 2236-7284. Disponível em: https://revistas.ufpr.br/direito/article/view/62962. Acesso $\quad$ em: 31 ago. $2019 . \quad$ DOI: http://dx.doi.org/10.5380/rfdufpr.v64i2.62962.
\end{abstract}

\section{RESUMO}

O presente artigo busca analisar a teoria desenvolvida pelos autores da escola de Yale, Robert Post e Reva Siegel, denominada Constitucionalismo Democrático. A teoria pretende ir na contramão dos estudos juriscêntricos e normativos predominantes na academia norte-americana, para desenvolver um aporte "positivo", ou seja, como de fato é, da interação entre constitucionalismo e democracia, compreendendo o fluxo dialógico que envolve o processo de legitimação da constituição. Neste, o desacordo não apenas é bem-vindo, como é constitutivo de tal legitimidade, não ameaçando o constitucionalismo como pretendem algumas teorias normativas. A análise desenvolvida neste trabalho, mais do que um esforço direcionado à academia do direito, contribui para uma melhor apreensão da democracia e do constitucionalismo brasileiros, uma vez que, de forma semelhante à realidade constitucional norte-americana, também temos a preponderância de entendimentos juriscêntricos precursores de uma identificação (equivocada) entre supremacia judicial e supremacia da constituição, a qual é evidenciada na postura protagonista e solipsista dominante no Judiciário nacional.

\section{PALAVRAS-CHAVE}

Constitucionalismo. Constitucionalismo democrático. Democracia. Jurisdição constitucional.

\begin{abstract}
This article aims to analyze the theory developed by the authors of the Yale school, Robert Post and Reva Siegel, called Democratic Constitutionalism. The theory intends to go against the juriscentric and normative studies prevailing in the American academy, to develop a "positive" contribution, as it is, of the interaction between constitutionalism and democracy, understanding the dialogical flow
\end{abstract}


that involves the process of the legitimation of the constitution. In this process, disagreement is not only welcome, but it is constitutive of such legitimacy, not threatening constitutionalism as some normative theories claim. The analysis developed in this work, rather than an effort directed to the law academy, contributes to a better apprehension of the Brazilian democracy and constitutionalism, since, similarly to the American constitutional reality, we also have the predominance of juriscentric understandings precursor of a (mistaken) identification between judicial supremacy and the supremacy of the constitution, which is evidenced in the protagonist and solipsist actuation that is dominant in the national judiciary.

\section{KEYWORDS}

Constitutionalism. Democratic constitutionalism. Democracy. Constitutional jurisdiction.

\section{INTRODUÇÃO}

O debate relativo à legitimidade do papel das cortes no processo democrático não é novidade na academia do direito e da ciência política, sendo um dos principais temas de discussão tanto no âmbito nacional, quanto no internacional. Grande parte dos estudos até então desenvolvidos, no entanto, levam adiante perspectivas normativas e juriscêntricas que se voltam ou à justificação do papel do judiciário enquanto guardião da constituição ${ }^{1}$ ou à sua descredibilização enquanto instituição não responsiva com a deliberação democrática, ambas insuficientes para apreensão da complexidade constitutiva da interação entre constitucionalismo e democracia.

Visando superar debates reducionistas e antagônicos como os supracitados, são crescentes os trabalhos acadêmicos que se preocupam em desenvolver a questão a partir de uma perspectiva positiva, como de fato é, do locus ocupado pela jurisdição constitucional em um Estado democrático e de direito. Dentre tais estudos, destaca-se o desenvolvido pelos autores da escola de Yale, Robert Post e Reva Siegel, em sua teoria do Constitucionalismo Democrático.

O Constitucionalismo Democrático surge como uma tentativa de superar visões maniqueístas da academia norte-americana centradas em polarizações entre direito e política, constitucionalismo e democracia, supremacia judicial e autogoverno do povo. Entendem Post e Siegel que tais fragmentações vão na contramão de um estudo comprometido do constitucionalismo, que tem em seu cerne a tensão construtiva entre estado de direito e democracia (POST; SIEGEL, 2007, p. 385).

Para os autores, as cortes, assim como as demais instituições, governo, movimentos sociais e o povo, são partes constitutivas do sistema político no qual estão imersas e em interconexão. Tal sistema faz parte de um projeto nacional assumido com a constituição e que está em processo contínuo

\footnotetext{
${ }^{1}$ Para os fins desse trabalho, usaremos o termo constituição com inicial maiúscula apenas quando estivermos nos referindo a uma constituição específica, por exemplo à Constituição de 1988.
} 
de evolução e significação, sendo aberto e inacabado e, porquanto, objeto constante de interpretação e de desacordos por parte dos membros da sociedade.

Como vivemos em uma sociedade plural, em que o que é sinônimo de uma vida boa para uns não o é para outros, por vezes existem desacordos tão profundos que a deliberação coletiva não é suficiente para solucioná-los. Nesses casos, recorre-se às cortes para dirimir a controvérsia. A resposta judicial, embora seja definitiva para o caso concreto, é apenas provisória em relação ao desacordo maior subjacente a ele. Ou seja, a decisão das cortes não encerra o debate político, não põe fim à possibilidade de que o povo, as demais instituições e o governo discordem do seu sentido.

A legitimidade da jurisdição constitucional, para a teoria de Post e Siegel, reside em sua responsividade democrática, ou seja, em sua habilidade de ser reconhecida, ainda que no futuro, como expressão da própria identidade do povo. Uma decisão judicial apenas será democraticamente legítima se for capaz de conquistar a aderência da sociedade ao sentido constitucional posto judicialmente, ainda que essa adesão venha a ocorrer em momento posterior da história.

Ainda que o Constitucionalismo Democrático tenha por objeto a realidade constitucional norte-americana, problemas e críticas semelhantes aos desenvolvidos pela teoria são pertinentes ao contexto brasileiro. Também no Brasil temos a predominância de entendimentos juriscêntricos precursores de uma identificação (equivocada) entre supremacia judicial e supremacia da constituição, que se desdobra na própria atividade das cortes. Estas, como instituição presumidamente “apartada” da política, adquirem legitimidade em sua suposta razão superior às das demais instituições democráticas, de modo que, enquanto voz superior, são incriticáveis e insuperáveis.

Nesse contexto, retomar a teoria de Post e Siegel de forma séria e comprometida mais do que um esforço direcionado à academia do direito e à teoria constitucional, contribui para uma melhor apreensão da democracia e do constitucionalismo brasileiros. Isso porque a análise vai além de perspectivas juriscêntricas da academia nacional que atribuem ao Judiciário a expectativa de messias na nação ${ }^{2}$ para, de forma diversa, entender o processo de legitimação da constituição como um fluxo contínuo de interação entre os membros judiciais e não judiciais da sociedade.

Para levar adiante o estudo proposto, serão reservados três momentos distintos de análise do Constitucionalismo Democrático, cada qual com a sua finalidade. No primeiro capítulo, buscaremos

\footnotetext{
${ }^{2}$ Conrado Hübner Mendes irá denominar essa cultura política de "retórica do guardião entrincheirado”, explicando que: "[a] mentalidade política que opera a interação institucional brasileira é dominada por uma 'retórica do guardião entrincheirado'. Atribui ao tribunal, ao menos no discurso, uma missão salvacionista na proteção de direitos e da reserva de justiça da democracia. [...] A cultura do guardião não é prejudicial apenas porque rejeita a participação genuína do legislador na formulação do significado constitucional, mas também porque lhe confere uma isenção de responsabilidade. Numa posição cômoda, não precisa preocupar-se com a constitucionalidade de seus próprios atos. Não se lhe demanda uma prestação de contas argumentativa” (MENDES, 2011, p. 229-230).
} 
situar a teoria de Post e Siegel no âmbito da filosofia constitucional, analisando sua interação com estudos e propostas de aporte semelhante. Nesse viés, confrontaremos o Constitucionalismo Democrático com o Constitucionalismo Popular e com o Constitucionalismo Popular Mediado, analisando as suas semelhanças e, principalmente, as suas diferenças, para, a partir desse intercâmbio, justificar a adoção do primeiro em detrimento dos demais.

Perpassada a sua contextualização ao lado de seus pares na filosofia constitucional, desenvolveremos, no tópico 2, o panorama geral da teoria, percorrendo suas principais construções teóricas e pretensões normativas. Tal análise busca, por um lado, explicitar os pontos-chave do estudo e, por outro, pretende afastar leituras consideradas equivocadas do Constitucionalismo Democrático, as quais, caso levadas adiante, podem comprometer todo o desenvolvimento discursivo proposto pelos autores de Yale.

Estabelecidas as bases do pensamento constitucional desenvolvido por Post e Siegel, o terceiro e último momento deste artigo será dedicado ao ponto mais importante do seu trabalho, qual seja, o papel do reconhecimento no processo de legitimação democrática da constituição e das cortes. É a partir do reconhecimento ou da filiação popular ao seu sentido que a constituição adquire legitimidade e autoridade em um constitucionalismo simultaneamente político e legal, em que a continuidade do projeto constitucional é atribuída tanto à sua preservação enquanto direito, quanto à sua sensibilidade aos valores fundamentais do povo. De forma semelhante, também as cortes devem estar abertas aos influxos desenvolvidos fora dos tribunais, uma vez que as decisões judiciais não encerram o debate constitucional, estando inseridas em um processo dialógico mais amplo que tem no reconhecimento a sua fonte de legitimidade.

Encerrando o estudo, situaremos, ainda no terceiro capítulo, o papel do engajamento popular e das reações (e contrarreações) das instituições não judiciais, backlash, no processo de disputa pelo sentido constitucional. Tal disputa, como veremos, é constitutiva de democracias plurais como a norte-americana e a brasileira, sendo fundamental para a legitimação do sistema políticoconstitucional.

\section{O DIÁLOGO ENTRE CONSTITUCIONALISMO POPULAR, CONSTITUCIONALISMO POPULAR MEDIADO E CONSTITUCIONALISMO DEMOCRÁTICO}

Para compreender o Constitucionalismo Democrático, faz-se necessário contextualizá-lo ao lado de seus pares na filosofia constitucional enquanto corrente de um pensamento mais amplo 
denominado constitucionalismo popular ${ }^{3,4}$. Este tem, em seu cerne, a democratização da interpretação constitucional, a qual é desenvolvida à luz de uma abordagem positiva ${ }^{5}$ da interação entre constitucionalismo e democracia.

As teorias positivas vão buscar entender a relação entre estado de direito (rule of law) e autogoverno (selfgovernment), bem como o papel da jurisdição constitucional nessa interação, sem fechar os olhos aos fatores que os conformam e tensionam ao longo do tempo. Procura-se, dessa forma, explicitar como o constitucionalismo e a democracia de fato dialogam e se condicionam na história política de um povo e não como deveriam (ou não) dialogar e se condicionar para que fossem discursivamente justificáveis.

Esta última forma de abordagem, de viés normativo, é sintetizada por Larry Kramer sob a concepção de constitucionalismo legal, o qual é contraposto ao constitucionalismo popular (KRAMER, 2004a, p. 959). Para Kramer, enquanto o constitucionalismo legal aloca no Judiciário a autoridade final de interpretar e aplicar a constituição, o constitucionalismo popular reconhece que o sentido constitucional se desenvolve em um espaço de debate mais amplo, que tem, como fonte última de legitimidade, o povo. Este não é tido como mero expectador das decisões judiciais, mas, sim, um participante ativo e legítimo, ao lado dos demais participantes constitucionais, responsável pela interpretação e aplicação da constituição.

No núcleo das discussões do constitucionalismo popular, está o questionamento da pertinência da oposição entre direito e política, que fundamenta os principais pilares das teorias normativas norte-americanas: a insulação dos juízes e a dificuldade de justificação do papel contramajoritário das cortes (FRIEDMAN, 2005, p. 258). Ao contrário dessas, o constitucionalismo popular não compreende o processo democrático de forma apartada e oponível ao constitucionalismo, mas seu principal interlocutor. Nesse viés, procura romper com a visão elitista de supremacia judicial,

\footnotetext{
${ }^{3}$ Ao longo deste estudo, a expressão constitucionalismo popular, com iniciais redigidas em letras minúsculas, será utilizada para designar um determinado pensamento constitucional que se opõe à visão constitucional levada a cabo pelas teorias normativas e juriscêntricas. Por outro lado, a utilização do termo Constitucionalismo Popular, com iniciais redigidas em letras maiúsculas, refere-se à teoria constitucional desenvolvida por Larry Kramer e Mark Tushnet e que será estudada ainda neste tópico.

${ }^{4}$ Classificação semelhante também adotada por Niembro (2013, p. 191-224).

${ }^{5}$ Como explica Friedman, o foco das teorias positivas "is not so much on how judges should behave, as on how they do and why. Positive theorists ask what motivates judges to decide cases as they do and what forces are likely to influence judges' decisions. The normative and positive projects have traveled on largely separate tracks, in part because the forces positive theorists identify as influencing judges commonly are political ones. 'Politics' is used here in a fairly capacious sense, referring to any influences on a judge's resolution of a case other than an independent judgment of the law as applied to the facts before the court. But the political forces identified by positive scholars are often quite base: Many positive theorists suggest that judicial ideology plays a significant role in how judges decide cases and that judges respond to pressures from other political actors. Positive scholars believe these forces play a large hand in shaping the content of the law, especially constitutional law" (FRIEDMAN, 2005, p. 258).
} 
segundo a qual os juízes são melhores intérpretes constitucionais e detentores da última palavra em direitos constitucionais, para retomar a importância da participação do povo na legitimação do estado de direito.

Enquanto correntes adeptas desse pensamento político-constitucional, temos o Constitucionalismo Popular, o Constitucionalismo Popular Mediado e o Constitucionalismo Democrático. O primeiro é desenvolvido pelos professores Larry Kramer (2004a) e Mark Tushnet (1999) e está pautado na limitação da supremacia judicial e na elaboração da doutrina constitucional enquanto agência coletiva. Sustentam os autores que, do caráter político-jurídico da constituição (e, portanto, não apenas legal), decorre a necessidade de suplantar a ideia de que os juízes seriam os únicos e melhores intérpretes constitucionais, cujas decisões se identificariam com a própria constituição.

Nesses termos, o sentido constitucional é descrito pelos autores como um projeto comum compartilhado por todos os membros da sociedade, e não apenas por uma instituição supostamente superior ${ }^{6}$. O protagonismo desse projeto é atribuído ao povo, que não tem sua atividade limitada a atos ocasionais de criação constitucional, mas a um controle ativo e contínuo da interpretação e implementação da constituição (KRAMER, 2004a, p. 959).

Kramer opõe o constitucionalismo popular à supremacia judicial, vistos como formas de organização constitucional mutuamente excludentes. Segundo o autor, uma constituição juriscêntrica, centralizada na última palavra judicial, desestimula a participação do povo na deliberação de questões constitucionais, incutindo, na sociedade, a ideia de que as cortes não podem ser contrariadas.

Ora, se os juízes possuem a palavra final em direitos constitucionais, ao povo e demais instituições não resta outro papel senão o de acatar passivamente as suas decisões, em uma relação de sujeição em que a interpretação dos primeiros silencia a dos segundos. Tal compreensão influencia não apenas a relação do Judiciário com os membros não judiciais da coletividade - relegando-os a uma posição de passividade -, mas também a atividade das próprias cortes que, cada vez mais, passam a estender o alcance de suas decisões a assuntos até então reservados ao debate político (KRAMER, 2004b, p. 228-233).

Ao contrário dos defensores da supremacia judicial, os quais, para Kramer, reproduzem discursos aristocráticos e mitigadores da importância do processo democrático - o qual é tido como algo ameaçador do constitucionalismo e do direito -, o autor defende uma constituição em que ninguém, incluindo o Judiciário, detém o monopólio sobre o seu sentido. Nesse contexto, o povo deve

\footnotetext{
${ }^{6}$ Diga-se que essa é a razão pela qual tal vertente do constitucionalismo é chamada "popular", porque distribui amplamente, entre os membros da coletividade, a responsabilidade sobre o sentido constitucional.
} 
reivindicar o seu papel legítimo de intérprete constitucional e de sujeito capaz do autogoverno, rechaçando a ideia de que a deliberação constitucional, por sua complexidade, não deveria ocorrer entre cidadãos comuns (KRAMER, 2004b, p. 247-248).

Vale dizer que a crítica de Kramer em relação à supremacia judicial não implica a defesa da exclusão das cortes do constitucionalismo, ainda que o professor condicione a sua atuação à autoridade final do povo, que pode (e deve) confrontá-la quando entender necessário. O que se critica, dessa forma, não é a voz judicial em si mesma, mas a sua exclusividade (soberania judicial) e seu caráter final (supremacia judicial), como última palavra, na interpretação da constituição .

Tushnet (1999), por outro lado, vai levar a referida crítica às suas últimas consequências ao propor até mesmo a erradicação dos tribunais. Em um determinado momento da sua obra, o professor de Harvard entende que a supremacia judicial é uma crença indefensável, na medida em que não haveria qualquer evidência de que as decisões judiciais sejam melhores ou, ainda, de que as cortes não possam errar.

$\mathrm{Na}$ verdade, Tushnet reconhece o erro como possibilidade inerente da atividade de interpretação da constituição, podendo ocorrer tanto no âmbito dos tribunais quanto dos demais membros não judiciais da sociedade (TUSHNET, 1999, p. 154-163). Nesse sentido, desconstitui um dos principais argumentos que milita em favor da supremacia judicial: a existência de uma racionalidade superior que orienta a atividade dos juízes pelos caminhos do direito em direção à melhor resposta.

Sustenta, o autor, ser necessário considerar a possibilidade de que o povo também possa atingir a proteção dos seus direitos por meio da política, retirando-se a constituição das mãos dos juízes. Isso porque, embora o controle judicial seja relevante na proteção das pré-condições do constitucionalismo popular e da democracia - como o direito de voto, a privacidade e a liberdade de oposição ao governo

\footnotetext{
${ }^{7}$ Inicialmente, Larry Kramer não vislumbrava na última palavra judicial problema à legitimidade do constitucionalismo, direcionando suas críticas à exclusividade (ou monopólio) judicial da interpretação constitucional. Nesse sentido, o autor explica que: "There is $[\ldots]$ a world of difference between having the last word and having the only word: between judicial supremacy and judicial sovereignty. We may choose to accept judicial supremacy, because we need someone to settle certain constitutional questions and, for a variety of historical and jurisprudential reasons, the Supreme Court seems like our best option. But it does not follow either that the Court must wield its authority over every question or that, when it does, the Court can dismiss or too quickly supplant the views of other, more democratic institutions. Nothing in the doctrine of judicial supremacy, in other words, requires denying either that the Constitution has qualities that set it apart from ordinary law, or that these qualities confer legitimate interpretive authority on political actors as a means of ensuring continued popular input in shaping constitutional meaning. The trick, of course, is to find the proper balance, a problem courts have struggled with throughout American history” (KRAMER, 2001, p. 13). No entanto, indo além da crítica desenvolvida nesse texto (KRAMER, 2001), centralizada na única palavra dos juízes, Kramer, posteriormente, também irá criticar o caráter final da decisão judicial, a qual, para ele, encerraria o debate constitucional. Assim, "(b)ear in mind that popular constitutionalism never denied courts the power of judicial review: it denied only that judges had final say" (KRAMER, 2004b, p. 208).
} 
-, assim como para lidar com situações de extrema injustiça, na prática, é impossível reduzir a tais pontos a sua tarefa (TUSHNET, 1999, p. 154-163). É por isso que, para Tushnet, o balanço entre os benefícios e prejuízos do controle judicial se inclinaria para a erradicação das cortes do constitucionalismo. Embora, é bom que se diga, em recentes trabalhos, ele vem alterando sua proposta radical de abolir o judicial review, optando por sua admissão desde que o Judiciário seja extremamente deferente ao Legislativo, e desde que o Parlamento possa reverter, de forma célere e fácil (isto é, por maioria simples), as decisões judiciais indesejadas ${ }^{8}$.

A segunda vertente do que aqui se chamou de constitucionalismo popular, categorização de uma forma peculiar de pensamento político-constitucional, consiste no Constitucionalismo Popular Mediado, o qual é desenvolvido pelo professor da escola de direito da New York University (NYU | Law), Barry Friedman. Enquanto “popular”, essa corrente, assim como as teorias de Kramer e Tushnet, pauta-se na reinserção do povo no processo de conformação do sentido da constituição, embora Friedman desenvolva a interação entre povo e cortes de forma distinta daqueles.

Para o autor, a discussão acerca da última palavra e de quem supostamente deveria detê-la se encontra ultrapassada. Ao invés de despender esforços com teorizações voltadas à separação entre direito e política e à justificação da insulação dos juízes, Friedman se preocupa em como os tribunais, de fato, decidem e quais os fatores que influenciam a sua decisão (FRIEDMAN, 2005, p. 257-260). Ou seja, não se trata de dizer quem deveria ter a última palavra ou de definir como as cortes deveriam decidir, mas de analisar o que motiva as decisões judiciais e qual o seu impacto na sociedade.

Subjacente à teoria de Friedman, está uma concepção de democracia que vai além da mera realização de preferências majoritárias, envolvendo uma compreensão mais profunda de política que leva em conta os grupos e interesses conflitantes de uma sociedade. Segundo essa visão, o objetivo da teoria constitucional não se reduz à escolha entre a regra da maioria ou da minoria - uma vez que ambas (co)existem em tensão contínua e dialógica -, mas, sim, na compreensão do papel das instituições, sobretudo do Poder Judiciário, a partir do ponto de vista positivo, consequencialista, do impacto de suas decisões na opinião popular (FRIEDMAN, 2009).

No Constitucionalismo Popular Mediado, os tribunais não estão alheios e imiscíveis à política, mas em constante diálogo com ela. No controle de constitucionalidade, há um intercâmbio inevitável entre opinião pública, imprensa, tribunais inferiores, instituições políticas, etc., que leva a

\footnotetext{
${ }^{8}$ Aqui, temos o caminho para formas alternativas de controle de constitucionalidade que ensejariam um sistema de controle de constitucionalidade fraco, na medida em que, da possibilidade de os juízes declararem a inconstitucionalidade de lei, não decorreria competir-lhes a última palavra (supremacia judicial), já que maiorias parlamentares ordinárias poderiam, de forma célere e constante, superar decisões judiciais que reputassem infelizes (BRANDÃO, 2012, p. 196-197).
} 
constituição para além do confinamento do direito. Tal influência não deslegitima a autoridade da decisão judicial, garantindo justamente a sua permanência em uma democracia plural marcada pela persistência de desacordos.

A palavra judicial não põe fim ao debate constitucional, não silencia, como sustentam Kramer e Tushnet, a voz do povo. Na verdade, as cortes, muitas vezes, catalisam o debate, colocando em pauta questões até então fora da agenda política, além de provocar as demais instituições a se pronunciar sobre determinado assunto. Aqui, não há a necessidade de devolver a constituição ao povo, na medida em que ela sempre esteve com o povo na ótica de um constitucionalismo popular mediado. Diante disso, a tese de Friedman é a de que há que se levar a constituição para além das cortes. Ademais, em longo prazo, as decisões judiciais acabam por refletir a opinião popular, em um processo dialético que envolve “decisão judicial - resposta popular - (re)decisão judicial” (FRIEDMAN, 2009). Com isso, a decisão é apenas o começo do processo dialógico. Portanto, a função central da revisão judicial, atualmente, é atuar como um catalisador para que o povo leve a sério a constituição.

Nesse contexto, Friedman desenvolve a analogia da “corda de bungee-jumping”, em que a opinião popular representa a base na qual a corda se encontra afixada e a interpretação judicial, a pessoa que irá realizar o salto. Para o autor, ainda que o Poder Judiciário, em sua atividade interpretativa, possa se distanciar da opinião popular, saltando para longe de suas convicções, a "corda de bungee-jumping” o puxará de volta para o seu ponto de partida, realinhando a sua decisão à visão do povo. A corda, nesses termos, representa a necessidade das cortes de obter “diffuse support”, ou seja, de conquistar apoio político e engajamento popular às suas decisões (FRIEDMAN, 2005, p. 327). Há, portanto, uma relação simbiótica entre a opinião popular e a revisão judicial, em que esta dialoga com e reforça aquela (FRIEDMAN, 2009).

Barry Friedman observa que nenhum acontecimento político ou decisão da Suprema Corte dos Estados Unidos se manterá sem o endosso do povo. A revisão judicial atua apenas como um mediador dessa relação política (tensão) que se expressa tanto de modo interno ao processo, como externo, a partir da reação às decisões pela opinião popular. A Suprema Corte norte-americana em regra sempre esteve em sintonia com a vontade do povo.

É, por isso, que o constitucionalismo popular de Friedman é “mediado”, porque o processo de formação do sentido constitucional é intermediado pelos tribunais. Esses facilitam o debate constitucional, sintetizando e organizando as principais visões da sociedade, as quais são reafirmadas, ainda que em longo prazo, pelas próprias decisões judiciais. Ou seja, para o autor, não apenas a jurisdição constitucional não se opõe à democracia, como é sua própria catalisadora, mediando o seu “caminhar para” em direção à consolidação da vontade popular. 
Em que pese o entendimento de Friedman de que as decisões dos tribunais devam refletir as preferências populares, o professor não sustenta a identificação da constituição com a vontade imediata do povo, tampouco o seu descompromisso com valores profundos existentes em sociedade. O tribunal deve, em algumas ocasiões, desviar-se da opinião popular em defesa de ideais caros ao projeto constitucional, sob pena de o constitucionalismo se equiparar à política comum (FRIEDMAN, 2003, p. 2.599-2.601).

A terceira e última corrente a ser estudada, o Constitucionalismo Democrático, é também o objeto de análise deste trabalho. Desenvolvido pelos professores norte-americanos da escola de Yale, Robert Post e Reva Siegel, o Constitucionalismo Democrático, assim como o Constitucionalismo Popular Mediado, não opõe a supremacia judicial ao constitucionalismo popular, propondo-se a analisar a sua interação de forma dialógica e construtiva (POST; SIEGEL, 2004, p. 1.027-1.044).

Para os autores, concepções mitigadoras da importância da voz judicial, em que esta é oposta ao constitucionalismo popular, partem de entendimentos simplistas da própria democracia, associando-a a formas precárias de agregação de preferências. Tais compreensões são afastadas para se desenvolver um aporte do princípio democrático que vá além da expressão da vontade da maioria. Para a teoria, a democracia apresenta em sua essência a realização do valor substantivo do autogoverno coletivo, demandando a observância das condições sob as quais os indivíduos participam da formação discursiva da vontade popular (POST; SIEGEL, 2004, p. 1.036).

A supremacia judicial não é oposta à democracia, assegurando as práticas e direitos necessários à autonomia popular. O constitucionalismo popular, por outro lado, articula os valores fundamentais da sociedade que orientam a atividade judicial ${ }^{9}$. Assim, tanto a supremacia judicial quanto o constitucionalismo popular contribuem de maneira indispensável para o funcionamento da democracia e da política constitucional, estando dialeticamente, e não antagonicamente, relacionados (POST; SIEGEL, 2004, p. 1.030).

Tendo isso em vista, o Constitucionalismo Democrático nos apresenta uma proposta mais refinada quanto ao papel das cortes no constitucionalismo. Os tribunais não são instituições antidemocráticas que se impõem em face dos demais membros da sociedade, relegando-os a uma posição insuperável de silêncio e passividade. Da mesma forma, não são meros reflexos da voz do povo, facilitadores (intermediadores) da opinião popular e de suas políticas públicas.

Na verdade, as cortes, assim como as demais instituições, movimentos sociais e o povo, são

\footnotetext{
${ }^{9}$ Nesse sentido, as cortes, no processo democrático, asseguram direitos constitucionais que são preconizadores de valores de importância transcendente necessários à própria democracia, sendo oponíveis tanto em face dos seus governantes, quanto das próprias cortes (POST; SIEGEL, 2004, p. 1.035).
} 
entendidas como partes distintas e interconectadas do sistema político no qual estão inseridas. Tal sistema faz parte de um projeto nacional (partilhado por todos) e de nação (enquanto ideal a ser atingido) assumido com a constituição e que está em processo contínuo de evolução e significação. Por ser aberto e inacabado, tal projeto é constantemente objeto de interpretação e de desacordos por parte dos seus membros, que devem se engajar no debate para persuadir uns aos outros quanto ao melhor resultado (POST; SIEGEL, 2007, p. 395).

No centro do debate constitucional não está o consenso entre cortes, povo e instituições, mas, exatamente, o contrário. É no desacordo que o constitucionalismo se desenvolve e se legitima em uma democracia, permitindo que os vários atores constitucionais interajam reciprocamente na reivindicação do sentido de constituição compatível com seu projeto individual e coletivo de vida. No entanto, como vivemos em uma sociedade plural, em que o que é sinônimo de uma vida boa para uns não o é para outros, existem desacordos tão profundos que a deliberação coletiva não é suficiente para solucioná-los; nesses casos, as cortes são provocadas a dirimir a controvérsia.

Embora a decisão judicial seja definitiva em relação ao caso concreto, ela é apenas provisória em relação ao desacordo maior subjacente a ele. Desse modo, a voz judicial não encerra o debate político, não silencia o povo, as demais instituições e o governo, muitas vezes, ampliando e elevando os parâmetros da discussão por meio de uma nova rodada procedimental de debates.

Nesse contexto, as cortes não são alheias à política, mas partes ativas em seu processo mais abrangente, atuando como catalisadoras do debate público institucionalizado e não institucionalizado. São também elas próprias influenciadas e conformadas pelas circunstâncias da política, que tensionam o Judiciário a reafirmar, por meio do direito, os valores e práticas fundamentais do povo (POST; SIEGEL, 2007, p. 395).

Ainda que Post e Siegel atribuam uma função mais significativa às cortes do que Kramer e Tushnet, os autores, assim como no Constitucionalismo Popular, conferem ao povo a autoridade final sobre a constituição. A legitimidade da jurisdição constitucional, para a teoria, reside em sua responsividade democrática, ou seja, em sua habilidade de ser reconhecida, ainda que no futuro, como expressão da própria identidade popular (POST; SIEGEL, 2007, p. 374). Uma decisão judicial, para Post e Siegel, apenas será democraticamente legítima se for capaz de conquistar a aderência da sociedade ao sentido constitucional posto judicialmente, ainda que essa adesão venha ocorrer em momento posterior da história. Não basta que as cortes decidam conforme o direito, devem também ser permeáveis às circunstâncias políticas que fazem parte da vida em sociedade.

São essas as linhas gerais desenvolvidas pelo Constitucionalismo Democrático, sendo certo que retomaremos a sua análise nos tópicos seguintes ainda desse capítulo. O objetivo desse primeiro 
momento não foi adentrarmos com profundidade no marco-teórico da pesquisa, mas analisar como ele interage, em seus principais pontos, com as demais vertentes do constitucionalismo popular.

Isso porque considerar o Constitucionalismo Democrático à parte desse diálogo seria ir de encontro à própria lógica desenvolvida pela teoria, que vê, no intercâmbio dialógico de posições, a premissa fundamental para a construção verdadeiramente democrática do pensamento constitucional. Dessa forma, apenas por meio do confrontamento das várias correntes do constitucionalismo popular, poderíamos deliberativamente (e não autoritariamente) nos filiar àquela desenvolvida por Post e Siegel, por apresentar uma compreensão mais refinada tanto da relação entre supremacia judicial e constitucionalismo popular, como do próprio locus das cortes nessa interação.

\section{DO CONSTITUCIONALISMO DEMOCRÁTICO: RECONSTRUINDO SUAS PREMISSAS BÁSICAS}

Se o tópico anterior se propôs a entender a relação externa do Constitucionalismo Democrático no âmbito da teoria constitucional, neste analisaremos como se desenvolve do ponto de vista interno, em suas pretensões normativas e construções teóricas.

O Constitucionalismo Democrático apresenta como premissa a tentativa de superar visões normativas da academia norte-americana, centradas em dicotomizações entre: direito e política, constitucionalismo e democracia, supremacia judicial e autogoverno do povo (POST; SIEGEL, 2007, p. 385). Nesse sentido, sustentam que a abordagem normativa, pautada na tradicional oposição entre a regra da maioria e a defesa judicial das minorias, desconsidera aspectos igualmente importantes do sistema constitucional, erigindo premissas que servem apenas para o conforto acadêmico. Exemplo disso está na ideia comumente reproduzida de que os juízes estariam insulados e alheios ao controle político, existindo na ordem constitucional enquanto fóruns de princípios. Ainda, a de que o direito seria capaz de restringir as decisões judiciais, afastando julgamentos políticos e as convicções pessoais dos magistrados ${ }^{10}$.

Em sentido diverso, mas igualmente normativo, está a pretensão de se transferir a última palavra em direitos fundamentais para o Legislativo, diante da falta de responsividade democrática das cortes. Nesse sentido, em vez de atribuir a deliberação constitucional a uma aristocracia judicial, pressupondo-se capacidades intelectuais superiores a uma minoria de juízes, o sentido constitucional

\footnotetext{
10 Dworkin (1977), por exemplo, desenvolve a distinção entre decisões de “política”, determinadas por processos políticos, e decisões de "princípio”, reservadas à primazia judicial. Ademais, também sustenta à insulação dos juízes, a qual os tornariam mais aptos à análise dos argumentos de princípio. Nesse sentido, “[a] judge who is insulated from the demands of the political majority whose interests the right would trump is, therefore, in a better position to evaluate the argument” (DWORKIN, 1977, p. 85).
} 
deveria ter seu locus de desenvolvimento no processo democrático, uma vez que erigido sob o manto da igualdade de voto (one man, one vote) (WALDRON, 1999).

Visando superar posições dessa natureza, as quais, ainda que em polos distintos de entendimento, estão centradas em tentativas normativas de justificar o constitucionalismo, o Constitucionalismo Democrático propõe um aporte positivo (“como de fato é”) do processo de formação do sentido constitucional, analisando as compreensões e práticas pelas quais a constituição é historicamente estabelecida em meio à controvérsia (POST; SIEGEL, 2007, p. 374). Tal análise é desenvolvida a partir de determinados pilares estruturantes, fundamentais para a compreensão do pensamento constitucional da teoria.

O primeiro deles decorre da própria perspectiva adotada no estudo, que, como dito, pretende ser positiva. Post e Siegel buscam ir além de idealizações de constitucionalismo, democracia e supremacia judicial, afastando também teorias da interpretação constitucional voltadas à obtenção do consenso, o qual geralmente é alcançado às custas da valorização de um intérprete constitucional (as cortes ou o parlamento) em detrimento dos demais (povo, movimentos sociais e demais instituições políticas).

Para os autores, o desacordo não é algo estranho ao constitucionalismo e, sim, parte constitutiva dele e de sua constante legitimação na democracia (POST; SIEGEL, 2009, p. 27). O conflito é inerente à disputa pelo sentido constitucional, e não uma ameaça à autoridade da constituição. Nessa disputa, o ativismo popular, por meio de reações e contrarreações às decisões judiciais, é uma das várias formas de reivindicação do sentido constitucional e de manutenção de sua responsividade democrática, dialogando e, simultaneamente, tensionando as cortes em direção aos seus valores mais profundos.

Desse modo, em sentido semelhante a outras teorias positivas ${ }^{11}$, o Constitucionalismo Democrático reconhece que, ainda que as cortes possam (e devam) levar a sério a lei e o direito, esses não são suficientes para impedir a influência de fatores políticos sobre a decisão judicial, sobretudo nos casos de maior repercussão e controvérsia em sociedade. As cortes não são alheias à política, fazendo parte da estrutura institucional na qual estão inseridas.

Direito e política, nesses termos, embora distintos, são também faces opostas e

\footnotetext{
${ }^{11} \mathrm{O}$ modelo atitudinal, por exemplo, por meio de uma análise empírico-comportamental da Suprema Corte americana, sustenta que os juízes tomam as suas decisões e emitem seus posicionamentos a partir de suas próprias convicções políticas e pessoais e não, como se acredita, pela melhor resposta segundo o direito. Ainda que o modelo atitudinal seja passível de críticas quanto à sua metodologia, não podemos desprezar o que dizem sobre a influência da política na atividade dos juízes e que é um dos pontos centrais de discussão das teorias de influência positiva (SEGAL; SPAETH, 2002).
} 
interconectadas de uma mesma moeda. Post e Siegel enxergam na sua reconciliação premissa básica do processo de legitimação da constituição, de modo a romper com tentativas de insulá-los ou opôlos um ao outro. Nesse sentido, desenvolvem uma abordagem que leva em conta as peculiaridades próprias de cada um, sem excluir ou mitigar a importância do outro, uma vez que ambos são valores constitutivos do sistema constitucional (POST; SIEGEL, 2002, p. 20).

Para o Constitucionalismo Democrático, política deve ser entendida como uma forma distinta de ordem social, que tem em seu cerne a persistência de desacordos vigorosos e inconciliáveis, pautados em uma relação de “agonismo” (MOUFFE, 2005). Em tal relação, os membros políticos (partidos políticos, movimentos sociais, povo, instituições) se reconhecem mutuamente enquanto adversários (e não inimigos), compartilhando uma mesma arena política, que é regida por um sistema de regras e leis comuns entre todos. Ou seja, o debate e o conflito, embora sejam inerentes à política, pressupõem o reconhecimento do outro enquanto participante legítimo, cujas posições devem ser respeitadas.

No debate político, há um acordo pré-estabelecido, em que seus membros concordam em discordar, de modo que, embora existam desacordos razoáveis e, muitas vezes, inconciliáveis, há um consenso de que todos fazem parte de um mesmo espaço público e de que devem nortear seus debates pelo uso pacífico da política. Nesse viés, a política não é uma guerra aberta, desprovida de regras (antagonismo ${ }^{12}$ ), ou um consenso já estabelecido (burocracia e direito), mas uma constante luta pelo acordo em condições em que são esperados e protegidos desacordos persistentes (POST, 2010, p. 23).

Direito, por sua vez, presume a existência de consensos. Invocamos o direito quando alguma concordância já foi atingida (ou acreditamos que o foi) quanto à relevância do valor protegido. Sob a forma de direito, conferimos exigibilidade e proteção aos valores considerados fundamentais à vida dos cidadãos, que passam a ser oponíveis em suas relações entre si, como na eficácia horizontal dos direitos fundamentais, e com o Estado.

Isso não implica dizer que o direito também não seria passível de desacordos, principalmente diante de normas de definição aberta e sentido amplo, como os direitos fundamentais. Podemos concordar sobre a relevância do direito à igualdade, mas discordar sobre a sua extensão material no reconhecimento do casamento homoafetivo ou do direito ao voto das mulheres. Da mesma forma, acordar pela garantia do direito à liberdade de expressão, mas discordar quanto aos limites do discurso de ódio ante a dignidade do indivíduo.

\footnotetext{
${ }^{12}$ No antagonismo, por sua vez, os oponentes no debate são considerados inimigos e, portanto, devem ser exterminados. Não há um sentimento de pertença a qualquer sistema (de regras, leis ou moral) que os identifiquem entre si (MOUFFE, 2005).
} 
Assim, para teorizarmos a relação entre direito e política, devemos entender que acordos e desacordos são fatos sociais persistentes tanto em um quanto em outro, ainda que em medidas distintas. Direito e política não são fenômenos distantes e incomunicáveis, mas práticas sociais com funções próprias de solidariedade voltadas à integração social. Embora sejam independentes, como abordagens distintas de uma mesma questão, são também interdependentes, necessitando-se reciprocamente.

Tal interação é também percebida no âmbito do constitucionalismo, em uma relação dialética em que não apenas a democracia depende do estado de direito, mas também este depende de formas democráticas de governo. A constituição, ao contrário de teorias que tentam segregar o seu caráter político e legal, não se limita à escolha de um ou de outro. Enquanto direito, espera-se que seja judicialmente assegurada e reforçada, garantindo-se direitos constitucionais, os quais são preconizadores de valores necessários à própria formação discursiva da vontade popular. Embora seja Lei Fundamental, a constituição é também a expressão dos compromissos mais profundos de uma sociedade, ou seja, política, estando em diálogo com sua história, memórias e, sobretudo, sua identidade (POST; SIEGEL, 2002, p. 25).

O Constitucionalismo Democrático reconhece que a permanência da constituição ao longo do tempo está condicionada à sua abertura para influências além do direito, entre elas as reivindicações sociais sobre o seu sentido. A constituição não subsiste em nossa sociedade de forma isolada e estranha aos valores e práticas que orientam a vida política. Pelo contrário, disputas sobre o seu sentido fazem parte da construção da identidade coletiva da nação, permitindo que os cidadãos se identifiquem uns com os outros e com a própria constituição. Por meio do debate constitucional, as diversas compreensões e visões políticas existentes em sociedade são confrontadas e tensionadas em um processo deliberativo inclusivo, em que todos estão legitimados a participar. O sentido constitucional, assim, não é algo a ser imposto autoritariamente pelas cortes, mas um projeto de todos.

Embora reconheçam a existência de tensões entre o estado de direito e a democracia, Post e Siegel os entendem como elementos interdependentes e indispensáveis ao sistema constitucional. De um lado, o princípio democrático, para que não se converta em um mecanismo de opressão das minorias (fascismo) e para a própria permanência dos seus valores no jogo político, depende da instituição de limitações e garantias pelo estado de direito. Este, por sua vez, a fim de adquirir legitimidade no ambiente democrático, deve ser capaz de dialogar com o espírito do povo e seus valores mais profundos, sem que isso implique sua conversão em um instrumento de maiorias ocasionais. Em suma, o Constitucionalismo Democrático explicita o paradoxo constitutivo da autoridade da constituição, relacionada, simultaneamente, à sua responsividade democrática e à sua 
legitimidade enquanto direito (POST; SIEGEL, 2009, p. 20).

Ainda que Post e Siegel não sejam expressos quanto ao modelo democrático adotado em sua teoria, é possível apreender do pensamento constitucional desenvolvido a pressuposição de uma democracia deliberativa. Esta é entendida como uma forma de governo pautada na exigência de justificação (reason-giving), em que todos os cidadãos - livres e iguais -, bem como os agentes governamentais, devem, reciprocamente, justificar as suas decisões.

Na democracia deliberativa, aqui trabalhada de forma ampla ${ }^{13}$, uma posição, seja ela judicial, legislativa ou popular, deve ser racionalmente justificada em um espaço dialógico e aberto, em que todos possam acessá-la e confrontá-la a partir de seus próprios entendimentos, os quais, igualmente, devem ser justificados. O processo público deliberativo, ainda que venha a produzir consensos dotados de estabilidade (provisória), não impede o seu questionamento e discussão posterior, mantendo-se aberto a novos debates (GUTMANN, 2004, p. 7).

Em política, bem como na vida prática em sociedade, os processos de tomada de decisão e o próprio entendimento humano são imperfeitos, não havendo certeza da correição das decisões para o presente e, menos ainda, para o futuro (GUTMANN, 2004, p. 6). Além disso, a tomada de decisão, ainda que se desenvolva em um ambiente dialógico e inclusivo, não é consensual, exigindo a escolha de uma posição dominante em detrimento de outra(s) sucumbente(s).

Diante disso, a abertura do processo deliberativo assegura não apenas a possibilidade de reversão de decisões tidas como equivocadas, como a própria legitimidade das posições alcançadas por meio do debate público, garantindo a filiação dos seus membros diante do conflito. Isso porque aqueles que não conseguirem fixar a sua visão e, por consequência, forem perdedores no debate, serão mais tendenciosos a aceitar a decisão caso acreditem na possibilidade de revertê-la ou modificá-la no futuro. Tal possibilidade apenas pode ser verdadeiramente alcançada garantindo-se aos integrantes a possibilidade de continuar a argumentar em favor de suas convicções e projetos políticos, em uma arena discursiva em que o desacordo seja bem-vindo.

Post e Siegel transpõem essa perspectiva para o Constitucionalismo Democrático ao atribuir a legitimidade e autoridade constitucional à sua capacidade de ser reconhecida como expressão da identidade do povo. Para os autores, é a possibilidade de persuasão do outro e, principalmente, das cortes, de sua visão constitucional que mantém a fidelidade popular à constituição, mesmo quando a sua posição não é prevalente (POST; SIEGEL, 2009, p. 27).

Ou seja, a crença na responsividade da ordem constitucional possibilita a perpetuação da

\footnotetext{
${ }^{13}$ Não pormenorizaremos os tipos de democracia deliberativa, uma vez que tal análise demandaria um estudo específico do tema, o qual não é o objetivo deste trabalho.
} 
constituição em meio a desacordos morais razoáveis, garantindo a filiação do povo ao seu sentido, ainda que esse seja contrário à sua compreensão individual de constituição. É a expectativa de um dia ver sua posição vencedora que mantém a adesão e a fidelidade dos cidadãos ao texto constitucional, dependendo da existência de mecanismos que lhes permitam expressar suas convicções e reafirmálas por meio das instituições que dizem o direito, sobretudo das cortes. "Paradoxically, the possibility of disagreement about the Constitution's meaning preserves constitutional authority, because it enables persons of very different convictions to view the Constitution as expressing their most fundamental commitments and to regard the Constitution as foundational law” (POST; SIEGEL, 2009, p. 27).

A jurisdição constitucional, nesses termos, não é vista como antagônica à democracia e ao exercício do autogoverno, mas, muitas vezes, a sua própria catalisadora. A decisão judicial é mais uma voz, ao lado das demais, no processo de interpretação constitucional, não encerrando o debate público democrático subjacente às principais controvérsias existentes em sociedade. A oposição popular ao sentido judicial não deslegitima a constituição e tampouco a própria jurisdição constitucional, fazendo parte do seu processo de legitimação no ambiente democrático (POST; SIEGEL, 2007, p. 375).

Embora reconheçam algum caráter final à decisão judicial, os autores atribuem a sua legitimidade à capacidade de ser reconhecida, ainda que no futuro, enquanto expressão da identidade do povo. Tal atribuição, como veremos, não implica a conversão das cortes em instituições representativas como os poderes políticos, mas a compreensão de que suas decisões fazem parte de um processo deliberativo mais amplo, responsável pela conformação do projeto constitucional coletivo ao qual todos (e não apenas os juízes) estão filiados.

No entanto, por sua relevância e centralidade na teoria, o “reconhecimento” será pormenorizado no tópico seguinte, no qual analisaremos as suas implicações nas concepções de constitucionalismo e jurisdição constitucional trabalhadas por Post e Siegel. Antes disso, faz-se necessário tecer algumas considerações finais sobre o pensamento constitucional desenvolvido pelos professores de Yale, sobretudo em função de algumas leituras equivocadas percebidas na academia brasileira, as quais, em determinados pontos, comprometem a construção discursiva do Constitucionalismo Democrático.

Ora, conforme já exposto, o Constitucionalismo Democrático não pretende desenvolver uma teoria da interpretação constitucional, sobretudo porque não vislumbra em tal metodologia relevância prática para a compreensão das interações conformativas da constituição. Ao atribuir a legitimidade das cortes (e da constituição) ao seu reconhecimento pelo povo, os autores não dizem como a decisão 
judicial deve ser justificada, tampouco prescrevem uma determinada conduta a ser observada pelos tribunais. Desse modo, Post e Siegel não se preocupam em endereçar como as cortes, do ponto de vista interno das suas decisões (em sua estrutura, alcance e justificação), serão sensíveis às reivindicações políticas e populares, reconhecendo, no entanto, que a ausência de tal sensibilidade compromete a sua legitimidade em uma democracia. Nesse viés, o Constitucionalismo Democrático se aproxima de uma teoria democrática da constituição e da jurisdição constitucional, voltada à análise dos processos externos de conformação do sentido constitucional e de legitimação das decisões judiciais.

Tal abordagem difere, por exemplo, da desenvolvida pelo minimalismo de Sunstein, direcionado, exatamente, à prescrição de uma conduta, no caso, minimalista, às cortes quando da interpretação constitucional. Sunstein (2001) desenvolve um modelo de decisão centrado nos valores da superficialidade (shallowness) e da estreiteza (narrowness), em que o primeiro determina que as decisões judiciais se esquivem de teorizações complexas e abstratas, prestigiando “acordos incompletamente teorizados"14; e, o segundo, que as cortes se atenham ao caso particular e específico subjudice, evitando posicionamentos sobre temas para os quais não foram provocadas (SUNSTEIN, 2001, p. 54).

Em defesa do minimalismo, Sunstein argumenta pela mitigação dos riscos que uma decisão judicial equivocada pode ensejar ao processo democrático, ressaltando o estímulo promovido ao seu desenvolvimento e amadurecimento ao deixar em aberto a discussão e a construção do significado constitucional. Para o autor, uma decisão minimalista expressa respeito às diversas posições existentes em sociedade, evitando a imposição sobre os cidadãos de uma visão constitucional contrária aos seus compromissos individuais. Nesse sentido, reduz a intensidade dos conflitos sociais e as reações negativas à própria decisão judicial, facilitando a aderência popular ao seu resultado.

Em suma, para o autor, as reações sociais à jurisdição constitucional são ameaças à autoridade e estabilidade da ordem constitucional, razão pela qual as cortes devem se esquivar de emitir pronunciamentos gerais e profundos, deixando para a deliberação democrática a responsabilidade sobre as principais controvérsias constitucionais existentes (SUNSTEIN, 2001, p. 59).

No núcleo do minimalismo judicial está a visão juriscêntrica de que as cortes encerrariam o debate democrático, retirando do espaço político a deliberação constitucional. Por isso, deveriam adotar uma posição minimalista, preservando a continuidade do debate público e o pluralismo

\footnotetext{
${ }^{14}$ Expressão traduzida do termo “incompletely theorized agreements” utilizado por Sunstein (2007, p. 2).
} 
democrático. Como vimos, o Constitucionalismo Democrático se recusa a aceitar tal ideia. As cortes não estão alheias às circunstâncias políticas nas quais estão inseridas, mas em constante diálogo com elas. Em suas decisões, devem ser sensíveis às diversas formas de reivindicação do sentido constitucional, entre elas as reações populares aos seus próprios pronunciamentos. Ademais, a voz judicial, embora final para o caso concreto, é apenas provisória quanto ao desacordo maior subjacente a ele, estando sujeita à revisão e superação.

Nesse sentido, há mais do que uma mera diferença de grau entre o papel das cortes no minimalismo judicial e no constitucionalismo democrático, de modo que a distinção é bem mais profunda ${ }^{15}$. Ora, o minimalismo está pautado em um modelo decisional de cunho juriscêntrico, em que o sentido constitucional é identificado à própria decisão judicial. Enquanto tal, a oposição a esta (decisão das cortes) implica uma necessária oposição à constituição, que coloca em risco a estabilidade e a coesão social. Por sua vez, o Constitucionalismo Democrático adere a um pensamento constitucional de cunho popular, orientado pela democratização da interpretação constitucional. Segundo este, reações sociais às decisões judiciais são constitutivas do processo de legitimação da constituição em uma democracia dinâmica e plural como as democracias modernas, tornando-a responsiva com os valores e práticas mais profundos do povo (POST; SIEGEL, 2007, p. 373-433).

Nesse viés, mais do que uma diferença metodológica quanto à adoção de uma teoria da decisão judicial, ou de grau, quanto ao protagonismo atribuído às cortes, o minimalismo e o constitucionalismo democrático são distintos em suas premissas fundamentais. Tentativas de aproximá-los sem os devidos cuidados quanto aos seus pensamentos constitucionais implicam o comprometimento de ambas as teorias, sobretudo do Constitucionalismo Democrático, que propõe exatamente se afastar de visões normativas e juriscêntricas existentes na academia norte-americana.

Ademais, quando Post e Siegel reconhecem virtudes ativas às decisões judiciais, elucidando os seus ganhos epistêmicos ao processo democrático, não estão propondo um ativismo judicial. Dizer que as cortes desempenham uma função própria no constitucionalismo e na democracia, assegurando direitos fundamentais aos cidadãos e estabilidade àqueles valores mais caros a uma determinada sociedade, não é o mesmo que dizer que devam assumir um protagonismo na interpretação constitucional. Esta compreensão, inclusive, é expressamente afastada pelos professores, que

\footnotetext{
15 Discorda-se, assim, da visão perfilhada por alguns autores, como Miguel Godoy (2017, p. 124-137). Para o autor brasileiro, embora os estudos norte-americanos sejam distintos em grau quanto à postura atribuída às cortes, aproximamse a partir da "proteção de um espaço público democrático e robusto, que leve em conta o pluralismo inerradicável e os profundos desacordos morais das sociedades contemporâneas” (GODOY, 2016, p. 131). Desse modo, "apenas a forma de abordar os conflitos e desacordos é que é diferente, mas não necessariamente oposta” (GODOY, 2016, p. 131).
} 
entendem a interpretação constitucional como um projeto de todos. Dessa forma, não se deve confundir as virtudes ativas das cortes, ou seja, os possíveis benefícios ao jogo democrático promovidos pela voz judicial, com a prescrição de uma postura ativista, “audaciosa” e preponderante do Judiciário.

Por fim, deve-se ressaltar que a atuação das cortes não está limitada à defesa de minorias ${ }^{16}$. O constitucionalismo democrático se afasta de pré-compreensões advindas da oposição entre direito e política, entre elas a polarização entre a regra da maioria e a defesa judicial das minorias. As cortes não estão limitadas a uma ou à outra, já que ambas coexistem no sistema político-constitucional. Dessa forma, embora não forneçam uma fórmula mágica de justificação das decisões judiciais, Post e Siegel desenvolvem uma visão constitucional que leva a sério o seu papel no constitucionalismo, analisando as diversas interações, confrontamentos e tensionamentos que fazem parte de sua legitimação.

\section{O RECONHECIMENTO NO CONSTITUCIONALISMO DEMOCRÁTICO: A LEGITIMAÇÃO DEMOCRÁTICA DA CONSTITUIÇÃO E DAS CORTES}

O terceiro e último tópico deste trabalho busca analisar o ponto central do Constitucionalismo Democrático, o reconhecimento. Este é desenvolvido como elo de legitimação da autoridade da constituição em meio a desacordos morais profundos, os quais são constitutivos das democracias plurais modernas. Nesse sentido, Post e Siegel atribuem ao reconhecimento a interface entre estado de direito e democracia, e, ainda, entre a supremacia judicial e o autogoverno do povo, que possibilita a responsividade da constituição e da jurisdição constitucional com os valores democráticos.

Já vimos, no tópico anterior, que as bases do Constitucionalismo Democrático se assentam na premissa de que a autoridade da constituição depende de sua legitimidade política e legal. A constituição deve preservar a sua condição de Lei Fundamental do ordenamento jurídico e, simultaneamente, ser sensível às reivindicações democráticas, inspirando os cidadãos a reconhecê-la como a sua constituição. Tal reconhecimento é sustentado por tradições de engajamento popular que possibilitam a democratização do sentido constitucional, o qual é visto como um projeto coletivo, que tem, como um de seus protagonistas, o povo.

Ao lado das cortes, instituições políticas e governo, o povo é reconhecido como intérprete

\footnotetext{
16 Nesse sentido, discorda-se da leitura de Maria Eugenia Bunchaft (2011), a qual atribui ao constitucionalismo democrático a defesa de uma atuação judicial condicionada à defesa das minorias.
} 
constitucional legítimo, capaz de reivindicar o sentido de constituição compatível com seus ideais de vida. Não apenas o povo, mas também as cortes e agentes governamentais, os quais igualmente participam da deliberação constitucional, por vezes, alinhando-se ao posicionamento popular, outras, confrontando o seu entendimento. Nesse processo, que certamente é permeado por inúmeros desacordos e conflitos, cada intérprete, cada qual com seus meios, dialoga e tensiona os demais a acatar a sua visão, em um debate agônico que é responsável pela conformação do sentido da constituição ao longo da sua história (POST; SIEGEL, 2007, p. 373-433).

A constituição, portanto, transcende os limites do direito, apresentando um componente político que reivindica a sua legitimação democrática. A legitimidade constitucional não é concebida como algo estático, dado a priori, e, sim, um fluxo contínuo entre o seu sentido e os valores fundamentais do povo, que tem como pilar a deliberação coletiva. Esta requer que as instituições permitam aos cidadãos se envolverem no processo de criação e interpretação do direito, mantendo-se abertas aos influxos populares.

Post e Siegel, no entanto, não são ingênuos ou superficiais quanto a essa influência e, por isso, antecipam que nem sempre o engajamento popular terá êxito na adesão das instituições à sua interpretação. A autoridade da constituição não resulta de uma identificação direta entre o seu significado e a opinião popular, mas de sua abertura às diversas formas de reivindicação do seu sentido, entre elas o backlash. Ou seja, não é a persuasão momentânea das cortes que garante a adesão dos cidadãos às decisões judiciais, mas a expectativa e a crença de influenciá-las em uma nova rodada procedimental de discussão (POST; SIEGEL, 2009, p. 27). Isso porque é o esforço e a esperança de persuadir e convencer as instituições que “dizem o direito" que provoca a mobilização, contramobilização, coalização e compromisso popular com os seus mandamentos.

Reconhecer o papel ativo da população na interpretação constitucional não implica adotar uma posição excludente ou mitigadora do Poder Judiciário, o qual é considerado intérprete igualmente legítimo, dotado de uma função relevante no sistema político-jurídico. Se a aderência da constituição ao espírito do povo garante a sua legitimidade e autoridade democrática como norma fundamental, a proteção judicial dos valores postos constitucionalmente lhe confere permanência e estabilidade ao longo do tempo.

A jurisdição constitucional, dessa forma, não é algo a ser oposto à democracia ou estranho e redutor dela, mas seu próprio catalisador, fomentando o debate político dentro e fora das instituições. A relação entre jurisdição constitucional e democracia é interdependente, de forma que a primeira fortalece a segunda. Nesse sentido, assim como as crenças constitucionais do povo são, muitas vezes, reforçadas pela interpretação judicial de direitos fundamentais, tornando-as exigíveis enquanto 
direito, também as decisões judiciais são inspiradas e sustentadas por ditas crenças, estando em constante diálogo com elas.

Ademais, Post e Siegel entendem que alguma forma de autoridade final das cortes é necessária ao constitucionalismo e à democracia, uma vez que certas condições devem ser preenchidas a fim de que os cidadãos possam verdadeiramente participar do debate público. Sem a garantia de igualdade, liberdade, de direitos sociais básicos, como a saúde e a educação, a deliberação se torna mero instrumento discursivo que não se sustenta na realidade. Os direitos constitucionais, nesse viés, asseguram aos cidadãos prerrogativas necessárias à reafirmação da sua participação livre e igualitária no espaço público de discussão. Sua proteção judicial é também uma garantia do princípio democrático (POST; SIEGEL, 2004, p. 1.035-1.036).

Além disso, a supremacia judicial desempenha uma importante função de estabilização e segurança da constituição, conferindo resposta a conflitos e divergências. Diga-se que supremacia judicial, para os autores, não é dizer que as cortes podem definir as crenças e os valores dos cidadãos ou, ainda, impor a sua interpretação sobre eles. Da mesma forma, também não representa impedimento à persecução, pelas vias legais e políticas possíveis, da visão popular, sendo este um processo legítimo e necessário ao constitucionalismo.

Assim sendo, diante de uma decisão judicial incompatível com o projeto constitucional ao qual estão filiados, os cidadãos devem buscar rechaçá-la; por exemplo, pressionando seus representantes políticos a propor emendas constitucionais que superem a interpretação judicial (overruling) ou, ainda, mobilizando-se, por meio dos movimentos sociais, para a persuasão da opinião popular e das instituições (backlash).

Percebe-se, assim, que em nenhum momento os autores propõem que a voz do Judiciário se sobreponha às demais vozes não judiciais ou que ocupe o lugar solitário na interpretação constitucional. Admitir que as cortes integram o constitucionalismo e que seu papel é relevante para o sistema não é o mesmo que lhes conferir qualquer tipo de protagonismo constitucional.

Na verdade, como já dito, no Constitucionalismo Democrático, a supremacia judicial não é antagônica ao exercício da democracia, mas uma garantia da sua própria efetivação, assegurando as práticas e direitos necessários à formação e à autonomia da vontade popular. Por outro lado, a democracia é o fundamento precípuo da autoridade das cortes e, por isso, embora as suas decisões ponham fim a um processo judicial, não encerram o debate público e democrático, sendo sempre provisórias, temporárias, precárias e sujeitas à revisão e superação. Em suma, a supremacia judicial não é identificada com a "última palavra” ou “a última autoridade” da corte para determinar o significado constitucional, sendo uma voz importante ao lado de outras na interpretação da 
constituição.

Apesar de Post e Siegel reconhecerem que as cortes apresentam uma forma distinta para declarar e fazer valer direitos, submetem a legitimidade judicial à sua responsividade democrática ou ao seu reconhecimento pelo povo (POST; SIEGEL, 2007, p. 374). Nesse viés, caso interpretem a constituição em termos que destoem profundamente das crenças dos cidadãos, as cortes podem ter seus pronunciamentos resistidos e confrontados nas demais áreas da vida pública, o que, caso tornado a regra, levará ao seu próprio estranhamento na democracia.

Ou seja, embora atribuam um papel importante às decisões judiciais na estabilidade e segurança do ordenamento político-jurídico, elas não são consideradas fenômenos alheios à política, mas em constante diálogo com essa. É do povo que o Judiciário e demais poderes estatais extraem a sua legitimidade, devendo ser a ele e à sua cultura sensíveis. Sua legitimidade, portanto, está no fino equilíbrio entre supremacia judicial e democracia, entre o direito “das cortes” e os valores constitutivos da cultura constitucional dos cidadãos (POST; SIEGEL, 2004, p. 1.038).

Embora a legitimidade das decisões judiciais esteja vinculada à sua capacidade de conquistar aderência popular, a supremacia judicial não se limita à estrita vontade do povo. Os tribunais não devem se converter em uma instituição representativa como é o Legislativo, mas compreender que a constituição tem uma importante dimensão política que também deve estar refletida na decisão. Por ser a autoridade da constituição simultaneamente política e legal, é de suma importância que, em suas decisões, as cortes estabeleçam conexões com a cultura política da nação, enquanto, simultaneamente, preservem o seu discurso técnico próprio de "pronunciar direito" (declaring law). "The Court, in short, must render interpretations of the Constitution that are ultimately responsive to the nation's political values, yet that remain recognizably law” (POST; SIEGEL, 2002, p. 26).

Ora, se a autoridade judicial depende de sua responsividade democrática, o que ocorre quando o direito pronunciado "nas cortes” confronta ou contraria a interpretação constitucional e os valores políticos dos membros não judiciais? Como dito, o backlash é um dos resultados possíveis.

Backlash, ou resistência popular, é uma das várias práticas de contestação de normas por meio das quais o povo busca influenciar o conteúdo do direito constitucional. Mediante a resistência popular, os cidadãos se engajam politicamente na reivindicação dos seus ideais e na persuasão das cortes, que, embora nem sempre seja exitosa, tensiona a interpretação judicial a observar os influxos desenvolvidos fora dos tribunais.

No Constitucionalismo Democrático, os movimentos sociais são uma das principais formas de organização e mobilização das reações populares, apresentando-se como importante canal de expressão das inquietudes, críticas e oposições populares às decisões judiciais e políticas 
governamentais (SIEGEL, 2006, p. 1.362-1.366).

Nesse sentido, ao servir de veículo às reivindicações populares, os movimentos sociais influenciam não apenas a relação do povo com as cortes (e demais intérpretes constitucionais), mas, a sua relação entre si, ou seja, como os membros de uma comunidade interagem e se identificam uns com os outros. Isso porque, para que consigam persuadir as instituições que “dizem o direito”, os cidadãos devem ser capazes de mobilizar e acomodar as diversas visões e ideais políticos existentes em sociedade, evitando desacordos sobre questões tidas como inconciliáveis.

Nesse sentido, ao compartilharem de um mesmo propósito, voltado à promoção e consolidação de valores e práticas caros à sociedade, os cidadãos são aproximados a partir de sua identificação coletiva, ou seja, de um sentimento de pertença que os torna membros de uma dada comunidade e não de outra. Tal identificação contribui não apenas para a legitimação democrática das instituições, como para o desenvolvimento solidário de uma comunidade normativamente heterogênea, em que o desacordo, embora permanente, não é visto como impedimento ao reconhecimento recíproco dos cidadãos (SIEGEL, 2006, p. 1.343).

Por outro lado, os movimentos sociais também impulsionam o debate público, desafiando os grupos favorecidos pela decisão a responder às suas reivindicações, em uma contramobilização ao seu próprio posicionamento. Nesse debate, cada movimento social é tensionado a argumentar suas posições em vista das considerações e críticas do outro, em uma relação de agonismo que requer, mesmo que indiretamente, o reconhecimento do seu oponente.

A apreensão dos argumentos contrários aos seus, ainda que para rebatê-los, contribui para o refinamento da visão constitucional levada adiante por cada movimento social, que é compelido a repensar, por meio das críticas, a sua própria posição e, por vezes, incorporá-las às suas reivindicações. Ademais, a interação entre mobilização e contramobilização, embora marcada pelo conflito, é também um canal de interação entre os movimentos sociais, que, apesar de suas diferenças, dividem um mesmo espaço de debate, reconhecendo mutuamente suas posições mesmo que para questioná-las perante a opinião popular e as instituições (SIEGEL, 2006, p. 1.362-1.366).

Dessa forma, os movimentos sociais expressam o confrontamento e a acomodação de posições constitucionais e políticas distintas, as quais se aproximam a partir do compartilhamento de uma identidade comum, a história da constituição e de seu povo. O êxito de suas reivindicações dependerá da sua capacidade de persuadir e conquistar a filiação das autoridades que “dizem o direito”, principalmente as cortes, uma vez que o processo legislativo da proposição de emendas constitucionais é mais moroso e complexo.

Pois bem, subjacente ao backlash, está a compreensão de que o direito constitucional, em 
longo prazo, é susceptível a influências políticas. Desse modo, uma desidentificação profunda e persistente entre o discurso profissional das cortes e os valores populares ameaça a legitimidade da jurisdição constitucional e da própria constituição (POST; SIEGEL, 2007, p. 378-379).

Ao contrário de autores que vislumbram no backlash uma ameaça ao constitucionalismo, os autores de Yale o veem como uma prática necessária ao seu processo de legitimação. Post e Siegel entendem que a participação popular é positiva para a ordem constitucional, constituindo uma das formas de fortalecimento da coesão social e da legitimação da constituição em uma sociedade plúrima de valores, convicções e ideais.

O engajamento do povo na deliberação constitucional reforça o seu compromisso com os valores constitucionais individuais e coletivos, o que mantém a sua adesão e fidelidade à constituição mesmo quando sua interpretação não é prevalente. Na tentativa de persuasão do outro e das instituições, os cidadãos apropriam-se de memórias e princípios compartilhados, permitindo que se identifiquem entre si e com a ordem constitucional.

Assim, o locus ocupado pelo povo no Constitucionalismo Democrático vai de encontro a tentativas de evitar o desacordo no sistema constitucional, já que é o conflito que permite a legitimação da constituição ao longo de sua história. A jurisdição constitucional, como vimos, não encerra ou silencia o processo político, mas pode exatamente catalisá-lo, ao fomentar o debate dentro e fora das instituições a partir de suas decisões. "Judicial review limits, channels, and amplifies democratic politics. Democratic politics, in turn, shapes the institution of judicial review” (POST; SIEGEL, 2007, p. 399). Portanto, é na tensão entre supremacia judicial, backlash, direito e política, que a constituição encontra seu reconhecimento e legitimação no constitucionalismo e na democracia, em uma interação dialógica e de agonismo marcada pela persistência de desacordos.

\section{CONCLUSÃO}

Ao longo deste artigo, retomamos o pensamento teórico e filosófico desenvolvido pelo Constitucionalismo Democrático, analisando-o em suas premissas básicas, assim como em diálogo com as teorias populares para aproximá-los em suas semelhanças, sem perder de vista as suas fundamentais diferenças.

Vimos que, ao contrário do que propõem teorias normativas e juriscêntricas da academia do direito e da ciência política, é no conflito que a constituição adquire sua legitimidade em uma sociedade plúrima de valores e ideais de vida, como, por exemplo, a brasileira. A tensão agônica entre direito e política ou entre cortes, representantes políticos, movimentos sociais e povo é construtiva 
para o projeto político de uma sociedade, o qual é aberto e inacabado e, portanto, passível de ser discutido, discordado e criticado.

Nesse contexto, a jurisdição constitucional não encerra ou silencia o processo político, mas pode exatamente catalisá-lo, ao fomentar o debate dentro e fora das instituições. Admitir que as cortes integram o constitucionalismo e que seu papel é relevante para o sistema não é o mesmo que lhes conferir qualquer tipo de protagonismo constitucional. $\mathrm{Na}$ verdade, como vimos, no Constitucionalismo Democrático, a supremacia judicial não é antagônica ao exercício da democracia, mas uma garantia da sua própria efetivação, assegurando as práticas e direitos necessários à formação e à autonomia da vontade popular. Por outro lado, a democracia é o fundamento precípuo da autoridade das cortes e, por isso, embora suas decisões ponham fim a um processo judicial, não encerram o debate público e democrático, sendo sempre provisórias, temporárias, precárias e sujeitas à revisão e superação.

Ou seja, apesar de reconhecerem a importância das decisões judiciais para a estabilidade e segurança do ordenamento jurídico, Post e Siegel não as consideram fenômenos alheios à política, mas em constante diálogo com essa. É do povo que o Judiciário e demais poderes estatais extraem a sua legitimidade, devendo ser a ele e à sua cultura sensíveis, por meio do reconhecimento de suas decisões pela sociedade.

Subjacente à possibilidade de reivindicação do sentido constitucional que se dá por meio da mobilização e contramobilização dos participantes judiciais e não judiciais, está a confiança de que se a melhor resposta não for alcançada no presente, será no futuro. É por tal razão que nos engajamos no debate e resistimos a interpretações judiciais e políticas que não refletem nossos valores fundamentais, porque acreditamos que nossa história constitucional voltará aos trilhos.

Reivindicar o sentido constitucional, entretanto, não é algo que parte de fora para dentro, de uma crítica ao outro sem olhar para si mesmo. Na verdade, perpassa uma autocrítica do projeto constitucional que estamos construindo, enquanto fontes de legitimidade da constituição.

\section{REFERÊNCIAS}

BRANDÃO, Rodrigo. Supremacia Judicial versus Diálogos Constitucionais. Rio de Janeiro: Lumen Iuris, 2012.

BUNCHAFT, Maria Eugenia. Constitucionalismo democrático versus minimalismo judicial. Revista Direito, Estado e Sociedade, n. 38, 2011. Disponível em: https://bit.ly/2YKfWwX. Acesso em: 24 abr. 2017. 
DWORKIN, Ronald. Taking rights seriously. Cambridge: Harvard University Press, 1977.

FRIEDMAN, Barry. Mediated Popular Constitutionalism. Michigan Law Review, Volume 101, Issue 8, p. 2.596-2.636, 2003.

FRIEDMAN, Barry. The politics of judicial review. In: Texas Law Review, vol. 84, nº 2, 2005. Disponível em: https://bit.ly/2MPt4dM. Acesso em: 17 out. 2016.

FRIEDMAN, Barry. The Will of the People: How public opinion has influenced the Supreme Court and Shaped the Meaning of the Constitution. New York: Farrar, Straus and Giroux, 2009 (eBook).

GODOY, Miguel. Devolver a Constituição ao povo: crítica à supremacia judicial e diálogos interinstitucionais. 2016. Tese (Doutorado em Direito) - Universidade Federal do Paraná, Curitiba, 2016. Disponível em: https://bit.ly/2YO9Vzb. Acesso em: 24 abr. 2017.

GUTMANN, Amy; THOMPSON, Dennis. Why Deliberative Democracy? Princeton: Princeton University Press, 2004.

KRAMER, Larry. Popular Constitutionalism, Circa 2004. California Law Review, vol. 92, n. 4, 2004a. Disponível em: https://bit.ly/31pDc0L. Acesso em: 6 abr. 2017.

KRAMER, Larry. The people themselves: popular constitutionalism and judicial review. New York: Oxford University Press, 2004b.

KRAMER, Larry. The Supreme Court 2000 Term Forward: We the Court. Harvard Law Review, v. 115, p. 4-169, 2001.

MENDES, Conrado Hübner. Direitos Fundamentais, Separação de Poderes e Deliberação. São Paulo: Saraiva, 2011.

MOUFFE, Chantal. On The Political: Thinking in action. New York: Routledge, 2005.

NIEMBRO, Roberto. Una Mirada al Constitucionalismo Popular. México: ISONOMIA, $\mathrm{n}^{\circ}$ 38, abril de 2013, p. 191-224.

POST, Robert. Theorizing Disagreement: Reconceiving the Relationship between Law and Politics. California Law Review, vol 98, 2010.

POST, Robert; SIEGEL, Reva. Democratic Constitutionalism. In: BALKIN, Jack; SIEGEL, Reva B. (org.). Constitution 2020. Oxford: Oxford University Press, 2009.

POST, Robert; SIEGEL, Reva. Popular Constitutionalism, Departmentalism and Judicial Supremacy. In: California Law Review, v. 92. Berkeley: Berkeley University, 2004, p. 1.0271.044.

POST, Robert; SIEGEL, Reva. Protecting the Constitution from the People: Juricentric Restrictions on Section Five Power. Faculty Scholarship Series, paper 182, 2002.

POST, Robert; SIEGEL, Reva. Roe Rage: Democratic Constitutionalism and Backlash. Faculty 
Scholarship Series. 169. 2007, p. 373-433. Disponível em: https://bit.ly/31v3UF5. Acesso em: 17 out. 2016.

SEGAL, Jeffrey A.; SPAETH, Harold J. The Supreme Court and the attitudinal model revisited. Cambridge University Press, 2002.

SIEGEL, Reva. "Constitutional Culture, Social Movement and Constitutional Change: The Case of the ERA”. In: California Law Review, vol. 94. Berkeley: University of California Press, 2006, p. 1.323-1.419.

SUNSTEIN, Cass R. One case at a time: Judicial minimalism on the Supreme Court. 2. ed. Cambridge: Harvard University Press, 2001.

SUNSTEIN, Cass. R. Incompletely theorized agreements. Chicago: Public Law and Legal Theory Working Paper, no 147, 2007.

TUSHNET, Mark. Taking the Constitution away from the Courts. Princeton: Princeton University Press, 1999.

WALDRON, Jeremy. Law and Disagreement. New York: Oxford University Press, 1999.

Ingrid Cunha Dantas

Mestre em Direito pela Universidade Federal de Minas Gerais - UFMG, com pesquisa com ênfase em Direito Constitucional e Teoria da Constituição. Bacharel em Direito pela UFMG. E-mail: dantas.ingrid@gmail.com

Bernardo Gonçalves Fernandes Pós-Doutor em Direito pela Universidade de Coimbra. Mestre e Doutor em Direito Constitucional pela UFMG. Professor Associado de Direito Constitucional na Faculdade de Direito da UFMG e na PUC-MINAS.E-mail: bernardogaf@yahoo.com 